\title{
DESCRIPTION OF TWO NEW SPECIES of Nippostrongylinae (Nematoda: Heligmonellidae) coparasites IN THREE SYMPATRIC SPECIES OF MASTOMYS SPP. (RODENTIA: MURIDAE) FROM SENEGAL
}

\author{
DURETTE-DESSET M.C.*, BROUAT C.**, DIOUF M.*** \& DUPLANTIER J.M.**
}

\section{Summary:}

Two new species of heligmosomoid Trichostrongylina nematodes belonging to the genera Neoheligmonella Durette-Desset, 1970 and Heligmonina Baylis, 1928 are described. They are parasitic in the small intestine of three species of Mastomys from Senegal living in sympatry: M. natalensis (Smith, 1834), M. erythroleucus (Temminck, 1853) and M. huberti (Wroughton, 1909).

Neoheligmonella granjoni $\mathrm{n}$. sp. is closely related to three species from Senegal. They concern: N. bai Diouf \& Durette-Desset, 2002 and N. dielmensis Diouf, Bâ \& Durette-Desset, 1998, both parasitic in Arvicanthis niloticus Geoffroy, 1903 and N. mastomysi Diouf et al., 1998, a parasite of M. erythroleucus. N. granioni n. sp. differs from these species by having 15 cuticular ridges at mid-body versus 13, a large carene and spicules taking up 10-15\% of body length versus $5.3-7.1 \%$. Heligmonina kanei n. sp. differs from the most related species H. kotoensis Diouf, Daouda \& Durette-Desset 2005, a parasite of M. natalensis from Benin in the following features: spicules taking up $11.6 \%$ of body length on average versus $16.8 \%$; a female tail three times longer than the distance anus-vulva versus a tail of equivalent size to this distance. In N. granjoni n. sp., where the material is abundant in all three hosts, the infra-specific variations observed (morphological or morphometrical) were not related to the host species. This is the first report of the genera Neoheligmonella and Heligmonina in M. huberti. The relevance of the phenomenon of host capture concerning the evolution of these two genera is confirmed.

KEY WORDS : Nematoda, Trichostrongylina, Heligmosomoidea, Heligmonellidae Neoheligmonella granjoni n. sp., Heligmonina kanei n. sp., Rodentia, Muridae, Senegal.
Résumé : DESCRIPTION DE DEUX NOUVELLES ESPÈCES DE Nippostrongylinae (Nematoda : Heligmoneliddae) coparasites CHEZ trois espèces De MASTOMYS (RODENTIA : Muridae) Vivant EN SYMPATRIE ET ORIGINAIRES DU SÉNÉGAL

Deux nouvelles espèces de Nématodes Trichostrongles Heligmosomoidea appartenant aux genres Neoheligmonella Durette-Desset, 1970 et Heligmonina Baylis, 1928 sont décrites. Elles parasitent l'intestin grêle de trois espèces de Mastomys vivant en sympatrie au Sénégal: M. natalensis (Smith, 1834), M. erythroleucus (Temminck, 1853) et M. huberti (Wroughton, 1909). Neoheligmonella granjoni $n$. sp est proche de trois espèces originaires du Sénégal. II s'agit de N. bai Diouf et DuretteDesset, 2002, N. dielmensis Diouf, Bâ et Durette-Desset, 1998, toutes deux parasites d'Arvicanthis niloticus Geoffroy, 1903 et N. mastomysi Diouf et al., 1998, parasite de M. erythroleucus. N. granjoni n. sp. se différencie de ces espèces par 15 crêtes cuticulaires au milieu du corps contre 13, une carène bien développée et des spicules représentant de 10 à $15 \%$ de la longueur du corps contre 5-3 à 7,1\%. Heligmonina kanei n. sp. se différencie de l'espèce la plus proche $\mathrm{H}$. kotoensis Diouf, Daouda et Durette-Desset, 2005, parasite de M. natalensis originaire du Benin par les éléments suivants: des spicules représentant en moyenne $11,6 \%$ de la longueur du corps contre $16,8 \%$; queve femelle trois fois plus longue que la distance anusvulve contre queue de longueur équivalente à cette distance. Chez N. granjoni n. sp., où le matériel est abondant chez les trois hôtes, les variations infra-spécifiques observées (morphologiques ou morphométriques) ne sont pas liées à l'espèce d'hôte. Les genres Neoheligmonella et Heligmonina sont signalés pour la première fois chez M. huberti. L'importance du phénomène de capture de I'hôte dans l'évolution de ces deux genres est confirmée.

MOTS CLÉS : Nematoda, Trichostrongylina, Heligmosomoidea, Helig monellidae, Neoheligmonella granjoni n. sp., Heligmonina kanei n. sp., Rodentia, Muridae, Sénégal.

genus are often dominant within small mammal communities, except in primary forests where they are restricted to human settlements. They undergo sporadic population explosions, transforming them into major agricultural pests (Leirs, 1994). Whilst rodents of the genus Mastomys are known to carry a number of important bacterial and viral diseases that are transmittable to humans (Gratz, 1997), their helminth communities are still poorly studied throughout most regions of their distribution. Recent studies have however been conducted on the helminth community structure of three species of Mastomys in South-eastern Senegal. (Brouat et al., 2007, Brouat \& Duplantier, 2007). In Senegal, the ecology of Mastomys species is well 
known due to the considerable work conducted since the eighties on their population dynamics and their ecological requirements (Hubert, 1982; Granjon \& Duplantier, 1989; Duplantier et al., 1996). Mastomys natalensis (Smith, 1834), M. erythroleucus (Temminck, 1853) and M. buberti (Wroughton, 1909) are morphologically closely related sibling species (Lecompte et al., 2002) but chromosomally well differentiated (Granjon et al., 1997). All three species occur in sympatry in south-eastern Senegal although living in markedly different habitats (Duplantier et al., 1997): M. natalensis is exclusively commensal in Senegal living inside villages; M. erythroleucus occurs mainly in fields and savannas, sometimes inside villages; $M$. huberti populations are rare and strictly localised around pools.

In initial studies conducted on parasite community structure of Mastomys spp. in south-eastern Senegal (Brouat et al., 2007; Brouat \& Duplantier, 2007), helminths were morphologically identified at the genus level. Helminth communities of the three Mastomys species consisted largely of the same taxa. 20 taxa were found with a majority of nematodes (11), then cestodes (8) (Brouat et al., 2007). Component helminth communities (two to ten taxa per sample site) were strongly dominated by nematodes with direct life cycles in each of the three host species, belonging to the genera Neoheligmonella, Trichuris or Syphacia (Brouat et al., 2007).

Two of the taxa found in each of the three Mastomys species of south-eastern Senegal were Trichostrongylina nematodes. It is the sole group for which systematic studies and species identification have been conducted in species of Mastomys. The two genera found in southeastern Senegal have already been reported as the sole members of the Trichostrongylina in species of Mastomys. They belong to the Ethiopian branch of the Nippostrongylinae (Heligmonellidae) and are parasites of Muridae. They concern Neoheligmonella Durette-Desset, 1970 and Heligmonina Baylis, 1928. In species of Mastomys, to date, four species of Neoheligmonella have been described, three of them in Mastomys erythroleucus: N. affinis (Baylis, 1928), N. mastomysi Diouf, Bâ \& Durette-Desset, 1998, N. skirringi Diouf et al., 1998 and one of them in Mastomys natalensis: N. lamaensis Diouf, Daouda \& Durette-Desset, 2005. All of these species originate from Western Africa (the Republics of Benin, Senegal, Congo and Central African Republic). In the genus Heligmonina, one species, H. bignonensis (Diouf, Ba \& Durette-Desset, 1997) has been described in M. erythroleucus from Senegal and three species in Mastomys natalensis: H. chabaudi (Desset, 1964), H. kotoensis Diouf, Daouda \& Durette-Desset, 2005, both from Western Africa (Senegal, Congo) and H. wakelini Durette-Desset, Digiani, Mahlaba \& Behnke, 2007 from the Republic of South Africa.

In the present paper, two new species are thus described from Mastomys spp, one belonging to the genus
Neoheligmonella and one belonging to the genus Heligmonina. Both were found in the three species of Mastomys living in sympatry in south-eastern Senegal, $M$. natalensis, $M$. erytroleucus and $M$. buberti. In several hosts, the two species are co-parasitic. Given the mass of specimens of the genus Neobeligmonella in the three hosts, living in sympatry, it seemed interesting to us to find out whether there was any infra-specific variations related to the host species. It is the first report of the genera Neoheligmonella and Heligmonina in M. huberti.

\section{MATERIAL AND METHODS}

S ampling was done in January 2004 in an area of about $1,300 \mathrm{~km}^{2}$ around the town of Kedougou $\left(12^{\circ} 33^{\prime} \mathrm{N}, 12^{\circ} 10^{\prime} \mathrm{W}\right)$ south-eastern Senegal, inside the Soudan-Guinean biogeographic area. A total of 502 Mastomys spp. were examined for gastro-intestinal parasites.

To determine the distribution of the parasites in the small intestine, it was divided into three equivalent parts, numbered SI 1 to SI 3 from the duodenum to the caecum. The worms were fixed in boiling $70 \%$ ethanol and stored in it until required for identification. The nomenclature used above the family group follows Durette-Desset \& Chabaud (1993). The nomenclature of the synlophe follows Durette-Desset (1985) and Durette-Desset \& Digiani (2005) and that of the caudal bursa follows Durette-Desset \& Chabaud (1981). The methods used in studying the synlophe follows DuretteDesset (1985). In order to study morphological and morphometrical variation in Neoheligmonella granjoni from the three host species, 10 males and 10 females were measured from one individual of each host species (Mastomys natalensis MNHN 599KX; M. erythroleucus MNHN $597 \mathrm{KX}$; M. huberti MNHN $598 \mathrm{KX}$ ). The morphological variations of the caudal bursa and the synlophe were taken from the same material. Measurements are in micrometers except where otherwise stated. Holotype and allotype were deposited in the collections of the Muséum national d'Histoire naturelle (MNHN) of Paris (France); the paratypes in the collections of the MNHN and the Laboratoire de Zoologie des Invertébrés Terrestres (ZIT) of Institut fondamental d'Afrique noire Cheikh Anta Diop of Senegal (IFAN Ch. A. Diop). The nomenclature of the hosts follows Musser \& Carleton (2005).

\section{RESULTS}

NEOHELIGMONELLA GRANJONI N. SP. (Figs 1-29)

Type-material: 189 males and females, coparasites of Heligmonina kanei $\mathrm{n}$. sp. 
Studied material: holotype male, allotype female, MNHN 599KXa, 10 male, 10 female paratypes, ZIT/IFAN $11 \mathrm{I}$, 10 male, 10 female paratypes MNHN $599 \mathrm{KXb}$.

Type-host: Mastomys natalensis (Smith, 1834) (Muridae, Murinae) Institut de recherche pour le développement (IRD), $\mathrm{n}^{\circ} \mathrm{CB} 108$.

Site: small intestine (SI. 1).

Type-locality: Ndebou ( $\left.12^{\circ} 31^{\prime} 05^{\prime \prime} \mathrm{N}, 12^{\circ} 26^{\prime} 01^{\prime \prime} \mathrm{W}\right)$, Kedougou, Republic of Senegal, January/04, Duplantier J.M. \& Bâ K. coll.

Etymology: the species is named in honour of Dr Laurent Granjon (IRD) for his work on systematics and ecology of African rodents.

Voucher material: many males and females parasites of $M$. natalensis, M. erythroleucus and $M$. huberti from the same region.

Prevalence and intensity of infection: in $M$. natalensis, 63 out of 220 (28.6\%) were infected, with one to 613 worms (mean =62.6); in $M$. erythroleucus 158 out of 263) $(60.1 \%)$ infected with one to 262 worms (mean = 29.6); in $M$. buberti 16 out of 18 (88.9\%) infected with 10 to 145 worms $($ mean $=116.8)$.

\section{DESCRIPTION}

Small nematodes with body coiled sinistrally along ventral side. Excretory pore situated within median third of oesophagus length. Deirids very much distally posterior to it (Fig. 1). Uterus length less than $20 \%$ of body length.

Head: cephalic vesicle present. In apical view, triangular oral opening with rounded corners, surrounded by two lateral amphids, four sub-median externallabial papillae and four sub-median cephalic papillae (Fig. 2).

Synlophe (studied in one male and one female paratypes, two males, two females from voucher material). In both sexes, body bearing longitudinal, uninterrupted ridges, all appearing just posterior to cephalic vesicle (Figs 7, 14) and disappearing about 100 anterior to caudal bursa in male and anterior to vulva in female. Carene present made up of two ridges with ventral ridge most developed. Number of ridges in $M$. natalensis: in both sexes 15 (carene, five dorsal, eight ventral) posterior to cephalic vesicle (Fig. 7), at level of oesophago-intestinal junction (Fig. 4), at mid-body
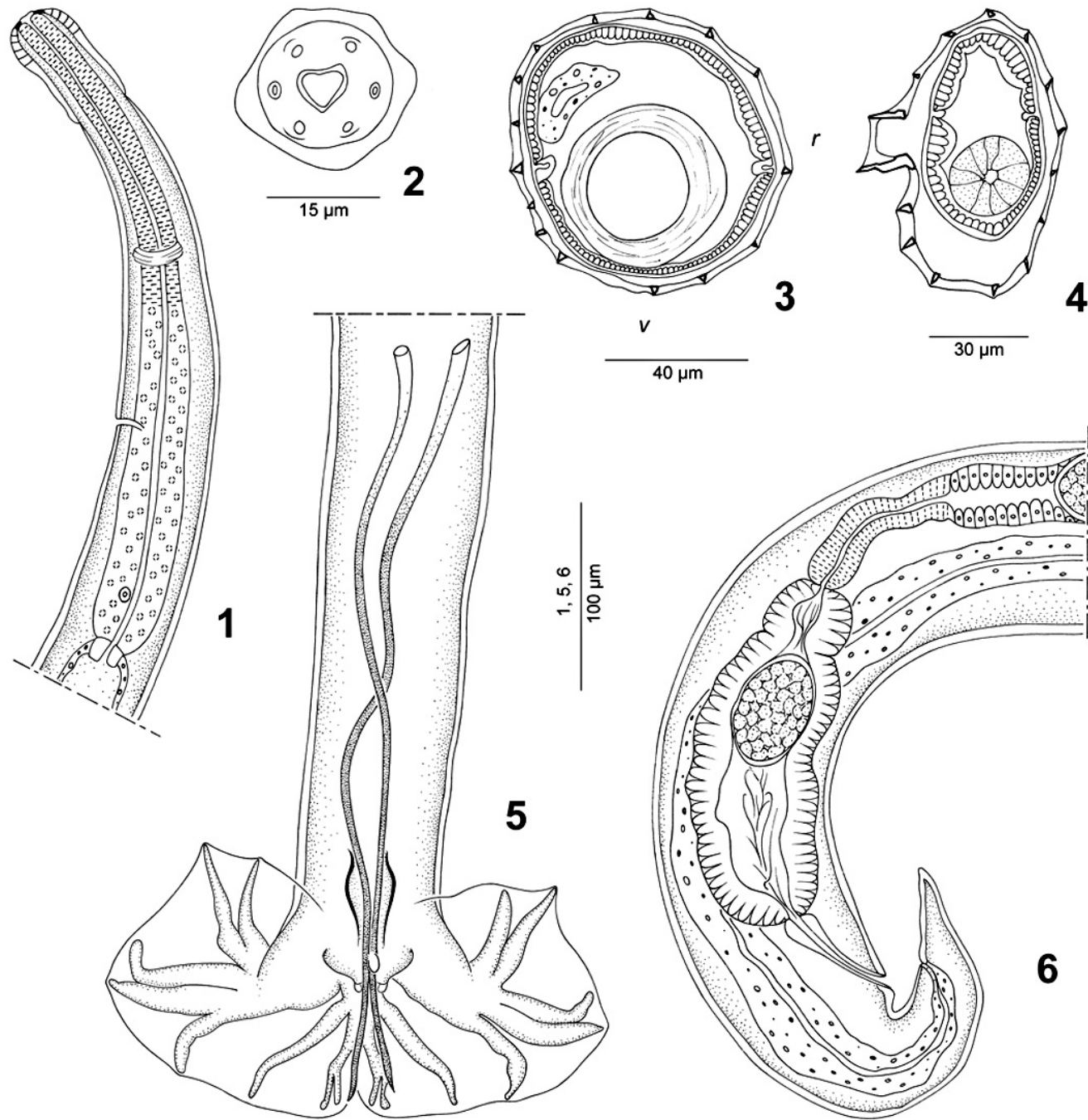

Figs 1-6. - Neoheligmonella granjoni $\mathrm{n}$. sp. from Mastomys natalensis (type host). 1 - female, anterior extremity, left lateral view. 2 - female, head, apical view. 3, 4 - transverse sections of body, 3 - female, at level of sphincter, 4 male, at oesophago-intestinal junction. 5 - male, caudal bursa, ventral view. 6 - female, posterior extremity, right lateral view. Abbreviations: v: ventral side ; r: right side. All sections are orientated as 3 . 
(Figs 18, 19) and up to disappearance of ridges, anterior to caudal bursa in male and anterior to vulva in female (Fig. 15). Number of ridges in M. erythroleucus and $M$. huberti: 15 (carene, five dorsal, eight ventral) posterior to vesicle cephalic in both hosts (Figs 7, 14), 14 (carene, five dorsal, seven ventral) at oesophagealintestinal junction in M. erythroleucus (Fig. 8), 15 in M. buberti (Fig. 15); 15 cuticular ridges at mid-body in both hosts (Figs 20-23). In posterior quarter of body, ridge $\mathrm{n}^{\circ} 8$ ' disappears at various levels (Figs 9, 12, 16) and the number of cuticular ridges (14) remains the same up to the caudal bursa and to the vulva. Gradient of size at mid-body present only on dorsal side, decreasing from right to left (Figs 18-23). On ventral side, ridges of left ventral quadrant more developed than those of right ventral quadrant (Figs 18-23). In male, ridges of equivalent size within posterior part of body (Figs 3, 12, 13). Double axis of orientation directed from ventral right to dorsal left quadrant. At midbody, in paratypes, right axis inclined at about $30^{\circ}$ to sagittal axis in male, $45^{\circ}$ in female; left axis inclined at about $70^{\circ}$ in male, $80^{\circ}$ in female. For inclination of the axes of orientation in voucher specimens, see Table III. In posterior part of male and in vulvar region, ridges orientated perpendicularly to body surface (Figs 3 , 12, 13).
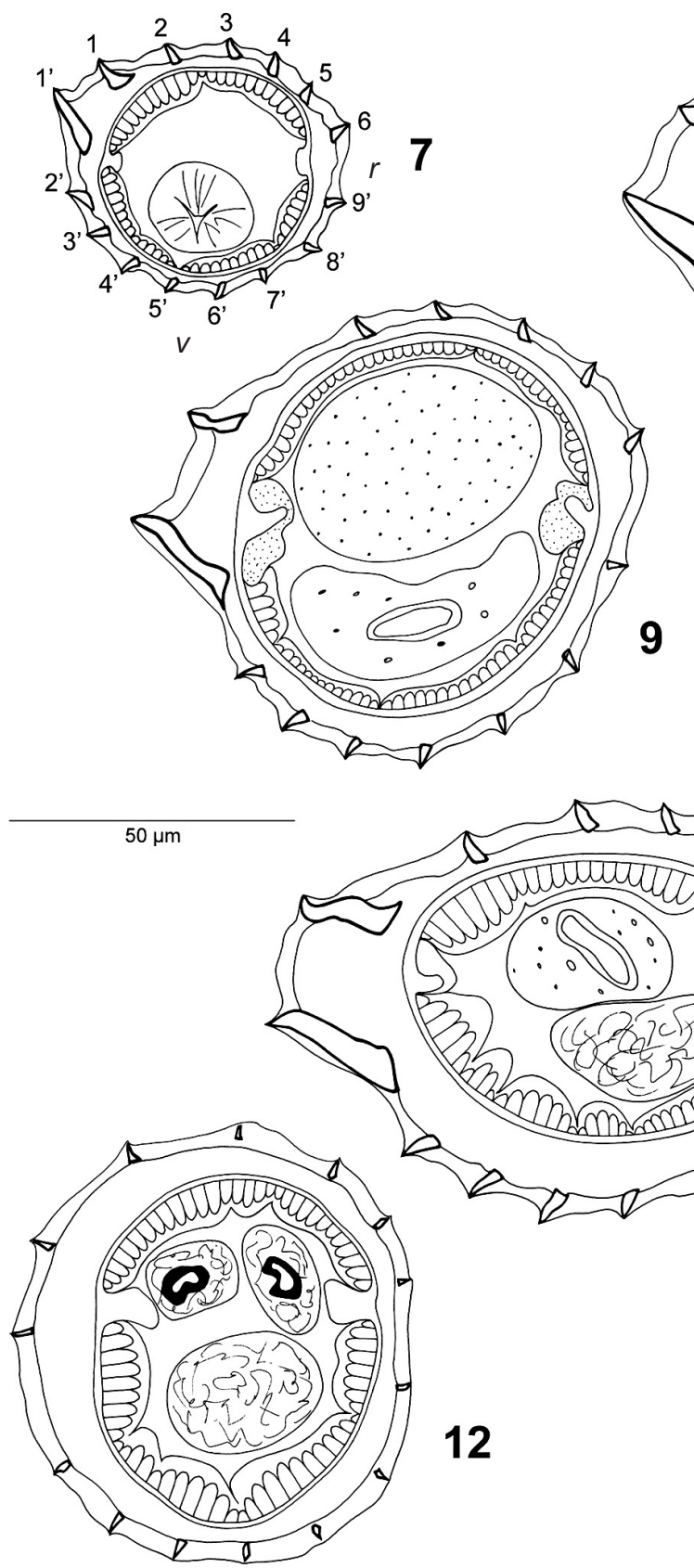

12 
. Holotype male: $3.85 \mathrm{~mm}$ long and 100 wide at midbody, carene included. Cephalic vesicle 80 long and 40 wide. Nerve-ring, excretory pore and deirids situated at 115,310 and 410 from apex, respectively. Oesophagus 490 long with muscular part 200 and glandular part 290.

Caudal bursa sub-symmetrical with pattern of type 23 due to presence of small common trunk of rays 2 to 6 with tendency to type 2-2-1 (Fig. 5). Prebursal papillae not observed. Rays 2 and 3 V-shaped or joined at various degrees with extremities always divergent. Extremities of rays 4 slightly curved forwards. Rays 4 and 5 divergent at extremity. Rays 8 arising symmetrically at base of dorsal ray. Dorsal ray divided at mid-length into two branches, each branch giving rise to two small branches rays 9 (external branches) slightly longer than rays 10 (internal branches) (Fig. 5). Thin alate sub-equal spicules 440 long ending in sharp tip (Fig. 5). Spicules taking up $11.5 \%$ of body length. Gubernaculum, 60 long and 20 wide at base in ventral view. Genital cone with elongated papilla 0 on ventral lip and two rounded papillae 7 on dorsal lip (Fig. 5).

Measurements (average and range) of ten paratype males: 3.4 (3.0-3.9) long and 100 (100-100) wide at mid-body, carene included. Cephalic vesicle, 71 (6580) long and 37.5 (30-40) wide. Nerve ring, excretory pore and deirids situated at 140 (110-180), 263 (200310), 405 (360-500) from apex, respectively. Oesophagus, 445 (400-520) long. Spicules, 426 (400-440) long. Spicules length/body length: 12.5 (11-14.7) \%. Measurements of males from voucher material: see Table I.

\begin{tabular}{lccc}
\hline & M. natalensis & M. erythroleucus & M. buberti \\
\hline Body length & $3,400(3,000-3,900)$ & $2,117(1,850-2,650)$ & $3,505(2,800-3,850)$ \\
Body width & $100(100-100)$ & $77(60-100)$ & $91(75-110)$ \\
Cephalic vesicle length & $71(65-80)$ & $52(42-60)$ & $58(55-60)$ \\
Cephalic vesicle width & $37.5(30-40)$ & $29(26-33)$ & $28(21-32)$ \\
Nerve ring/apex & $140(110-180)$ & $141(110-160)$ & $172(140-210)$ \\
Excretory pore/apex & $263(200-310)$ & $204(140-260)$ & $256(200-310)$ \\
Deirids/apex & $405(360-500)$ & $326(140-250)$ & $265(205-310)$ \\
Oesophagus length & $445(400-520)$ & $333(300-350)$ & $392(330-450)$ \\
Spicule length & $426(400-440)$ & $33(30-55)$ & $401(380-430)$ \\
Gubernaculum length & $48(40-60)$ & $18(15-22)$ & $51(30-60)$ \\
Gubernaculum width & $25(20-40)$ & 10 & $22.5(20-28)$ \\
Number of specimens & 10 & 10 \\
\hline
\end{tabular}

Table I. - Measurements (average and range) of 30 male specimens of Neoheligmonella granjoni n. sp. from Mastomys natalensis (type host) (MNHN $599 \mathrm{KX}$ ), from M. erythroleucus (MNHN $597 \mathrm{KX}$ ) and from M. buberti (MNHN $598 \mathrm{KX}$ ). All measurements are in micrometres.
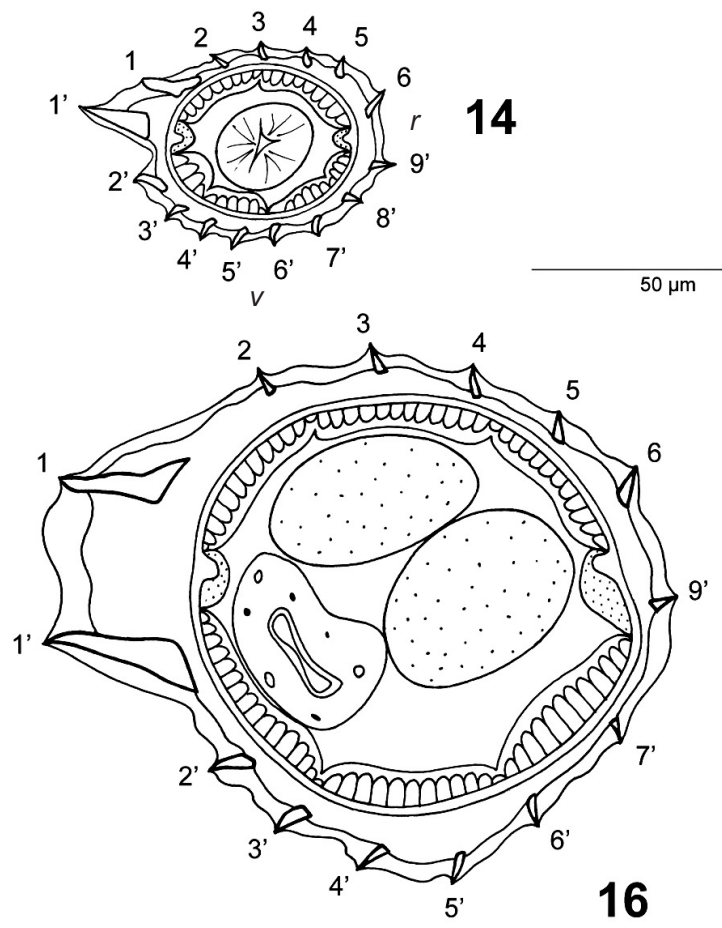

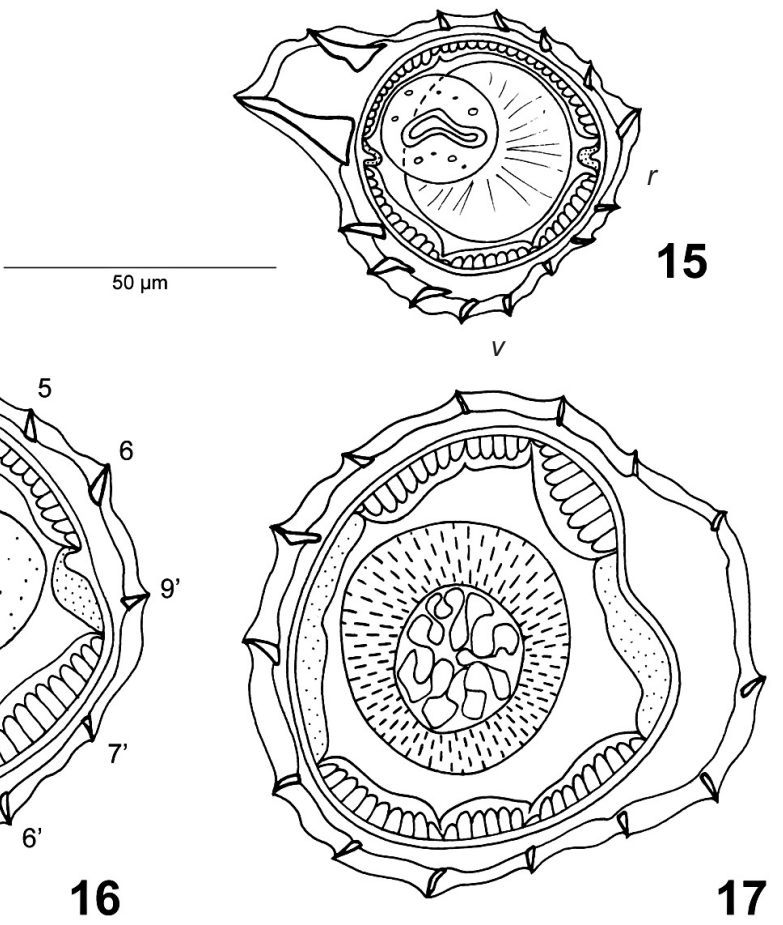

Figs 14-17. - Neoheligmonella granjoni $\mathrm{n}$. sp. from Mastomys huberti. Transverse sections of body. $14-$ 15 - male, $3.6 \mathrm{~mm}$ long, 14 - just posterior to cephalic vesicle, 15 - at level of the oesophageal intestinal junction. 16-17 - female. $4.7 \mathrm{~mm}$ long, 16 - at 1.1 $\mathrm{mm}$ anterior to vulvar opening, 17 - at level of the distal infundibulum.

Abbreviations: $v$ : ventral side ; $r$ : right side. All sections are orientated as 14 . 
- Allotype female: $4.2 \mathrm{~mm}$ long and 100 wide, carene included. Cephalic vesicle 60 long and 40 wide at base. Nerve-ring, excretory pore and deirids situated at 160, 330 and 490 from apex, respectively. Oesophagus 560 with muscular part 210 and glandular part 350 (Fig. 1). Monodelphic. Vulva situated at 180 from caudal extremity. Vagina vera 60 long. Ovejector 310 long with vestibule 170 long, sphincter 40 long and infundibulum 100 long (Fig. 6). Uterus 600 long taking up $14.3 \%$ of body length, containing eight eggs at morula stage, 60 long and 40 laid out in one row. Tail conical, 50 long. Measurements (average and range) of 10 paratype females: 3.6 (3.1-4.2) $\mathrm{mm}$ long and 102 (100-110) wide at mid-body, carene included. Cephalic vesicle 69.5 (60$75)$ and 39.5 (35-40) wide. Nerve ring, excretory pore and deirids situated at 123 (100-150), 281 (210-360), 413 (330-520) from apex, respectively. Oesophagus 483 (440-580) long. Vulva situated at 176 (140-200) from caudal extremity. Vagina vera 44 (40-60). Ovejector 303.5
(280-335) long with vestibule 165 (130-220) long, sphincter 36.5 (30-45) long and infundibulum 102 (80-120) long. Uterus 617 (500-700) long, taking up 17 (15-19) \% of body length. Number of eggs 10 (7-12), 77 (79-90) long and 50 (40-60) wide; tail 50 (45-70) long.

Measurements of females from voucher material: see Table II.

- Morphological variations observed in the three host species

Synlophe (Figs 18-23). The synlophe in the three hosts was compared at mid-body since in the anterior and posterior parts of the body, mainly in the female, infraspecific variations are frequently observed within the same host. At mid-body, there is no variation concerning the number of the cuticular ridges nor the relative size of the ridges and the position of the axes of orientation. In every case, the axes pass through ridge $n^{\circ} 7^{\prime}$ and $n^{\circ} 8$ ' for the right side and ridge $n^{\circ} 1$ and
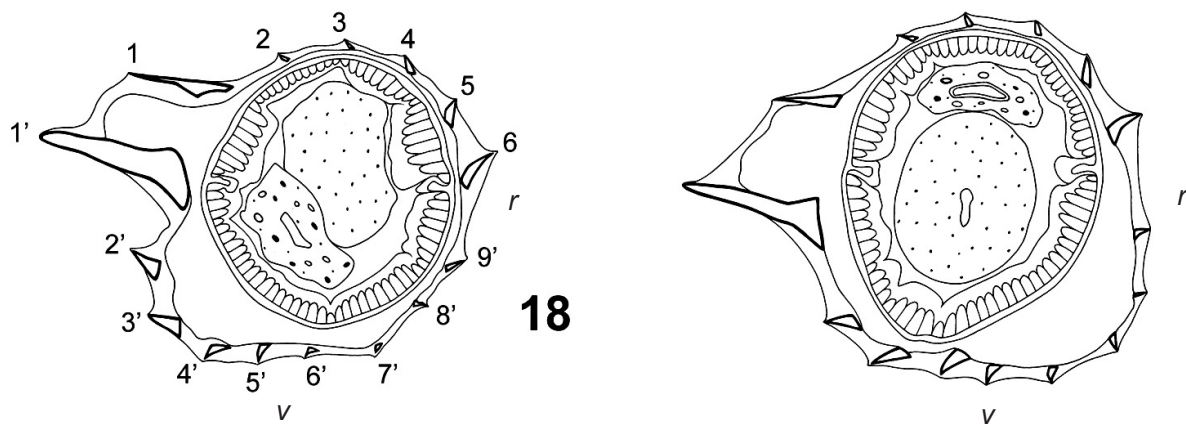

19

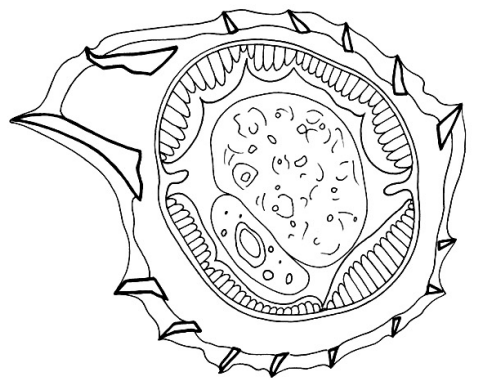

20
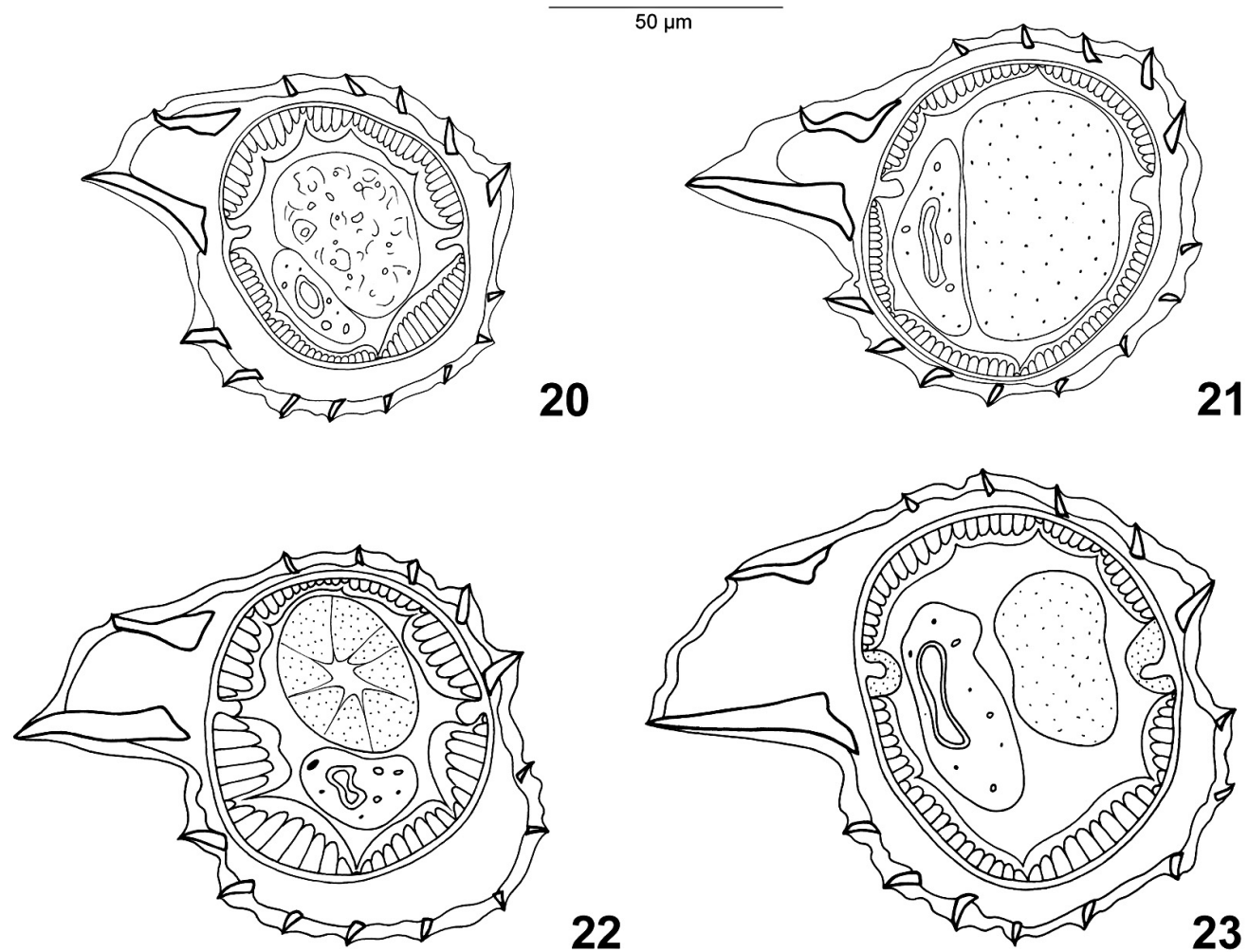

22

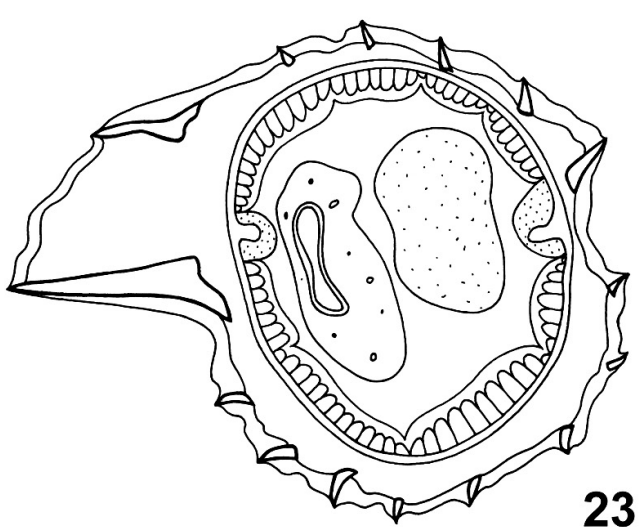

Figs 18-23. - Neoheligmonella granjoni $\mathrm{n}$. sp. Transverse sections at mid-body. 18-19 - from Mastomys natalensis. 20-21 - from $M$. erythroleucus. 22-23 - from M. huberti. 18, 20, 22 males. 19, 21, 23 - females. Abbreviations: $v$ : ventral side ; $r$ : right side. All sections are orientated as 18 . 
$\mathrm{n}^{\circ} 1^{\prime}$ for the left side. At mid-body in both sexes, the inclination of the axes varies according to the hosts, but these variations are also observed within the type material (Figs 18-23 ; Tables III).

Caudal bursa (Figs 24-29). In all three hosts, the caudal bursa pattern is of type 2-3 with a tendency to type 2-2-1. This means that rays 2 and 3 on the one hand and 4 to 6 on the other hand have a common trunk (type 2-3), but rays 6 separating first from this common trunk and rays 4 and 5 diverging only at their extremities, the caudal bursa pattern tends to type 2-2-1. The observed variations concern only the length of the common trunk of rays 4 to 6 and are present in the specimens from the three hosts. The length of the common trunk 4-6 varies in specimens from the three hosts and concern indistinctly both lateral lobes (Figs 24, 26, 27).
The shortening of the common trunk can be reduced to the width of ray 6 (Figs 25-29), then rays 3 and rays 6 diverging at the same level from the common trunk of rays 2-6, the pattern of type 2-2-1 is observed. This is the single case found in a specimen parasite of M. erythroleucus (Fig. 28).

- Morphometrical variations observed in the three host species (Tables I-II-III)

The parasites of $M$. erythroleucus are the smallest. The position of the excretory pore is variable within each host. The position of the deirids is very posterior in the parasites of $M$. natalensis.

\section{DiAGNOSIS}

The specimens described above belong to the genus Neoheligmonella Durette-Desset 1971 (Heligmonelli-

\begin{tabular}{lccc}
\hline & M. natalensis & M. erythroleucus & M. buberti \\
\hline Body length & $3,580(3,050-4,200)$ & $2,960(2,250-3,750)$ & $79(65-100)$ \\
Body width & $102(100-110)$ & $56(42-70)$ & $(4,150-5,300)$ \\
Cephalic vesicle length & $69.5(60-75)$ & $31(25-40)$ & $62(50-120)$ \\
Cephalic vesicle width & $39.5(35-40)$ & $149(120-190)$ & $32(25-40)$ \\
Nerve ring/apex & $122(100-150)$ & $216(180-260)$ & $193(170-220)$ \\
Excretory pore/apex & $281(210-360)$ & $230(210-270)$ & $298(270-330)$ \\
Deirids/apex & $413(330-520)$ & $364(250-460)$ & $337(295-435)$ \\
Oesophagus length & $483(440-580)$ & $119(80-160)$ & $437(410-465)$ \\
Vulva/caudal extremity & $176(140-200)$ & $127(92-160)$ & $147(140-160)$ \\
Vestibule length & $165(130-220)$ & $37(30-45)$ & $139(110-160)$ \\
Sphincter length & $36.5(30-45)$ & $115(70-160)$ & $39(30-45)$ \\
Infundibulum length & $102(80-130)$ & $602(430-740)$ & $128(90-170)$ \\
Uterus length & $617(500-700)$ & $676(510-860)$ \\
Eggs length x eggs width & $10(7-12)$ & $8(5-12)$ & $60(55-75) \times 39(30-45)$ \\
Number of eggs & $58(45-70)$ & $44(30-55)$ & $7(2-11)$ \\
Tail length & 10 & 10 & $67(61-72)$ \\
Number & $(70-90) \times 50(40-60)$ & 10 \\
\hline
\end{tabular}

Table II. - Measurements (average and range) of 30 female specimens of Neoheligmonella granjoni n. sp. from Mastomys natalensis (type host) (MNHN $599 \mathrm{KX}$ ), from M. erythroleucus (MNHN $597 \mathrm{KX}$ ) and from M. buberti (MNHN $598 \mathrm{KX}$ ). All measurements are in micrometres.

\begin{tabular}{|c|c|c|c|}
\hline & M. natalensis & M. erytbroleucus & M. buberti \\
\hline Neobeligmonella granjoni & Males & Males & Males \\
\hline Exc. pore/oesophagus L & 47.6 to $65.2 \%$ & 57 to $84 \%$ & 57.8 to 79.5 \\
\hline Deirids/oesophagus L & 89 to $96 \%$ & 40 to $76 \%$ & 62 to $79 \%$ \\
\hline Oesophagus LA/body L & 10 to $15 \%$ & 11 to $18 \%$ & 10.5 to $17.9 \%$ \\
\hline Spicule LA/ body L & 11 to $15 \%$ & 11 to $18 \%$ & 10.3 to $13.9 \%$ \\
\hline Inclination of $\mathrm{RA} / \mathrm{SA}$ & $30^{\circ *}, 60^{\circ * *}$ & $48^{\circ}$ & $50^{\circ}$ \\
\hline \multirow[t]{2}{*}{ Inclination of LA/SA } & $70^{\circ *}, 90^{\circ * *}$ & $67^{\circ}$ & $82^{\circ}$ \\
\hline & Females & Females & Females \\
\hline Ex. pore/oesophagus L & 44 to $69 \%$ & 57 to $72 \%$ & 66 to $71 \%$ \\
\hline Deirids/oesophagus L & 75 to $92 \%$ & 59 to $65 \%$ & 71 to $73 \%$ \\
\hline Oesophagus L/body L & 10.5 to $15.7 \%$ & 10 to $14 \%$ & 7.9 to $10.1 \%$ \\
\hline Uterus L/body L & 16 to $19 \%$ & 16 to $26 \%$ & 10.5 to $17.9 \%$ \\
\hline Inclination of RA/SA & $45^{\circ *}, 45^{* * *}$ & $52^{\circ}$ & $65^{\circ}$ \\
\hline Inclination of LA/SA & $84^{\circ *}, 80^{\circ * *}$ & $82^{\circ}$ & $82^{\circ}$ \\
\hline
\end{tabular}

Abbreviations: L: length; RA: right axis of orientation; LA: left axis of orientation; SA: sagittal axis.

Measurements of the inclination of the axes of orientation in Mastomys natalensis: * from type material, ** from voucher material.

Table III. - Comparative ratios of some measurements of Neoheligmonella granjoni n. sp. in Mastomys natalensis (type host), M. erythroleucus and $M$. buberti. 

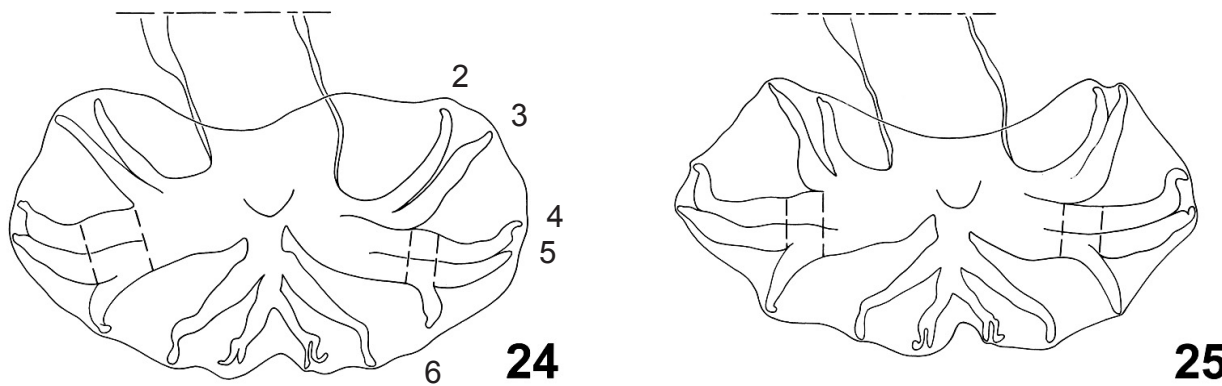

25
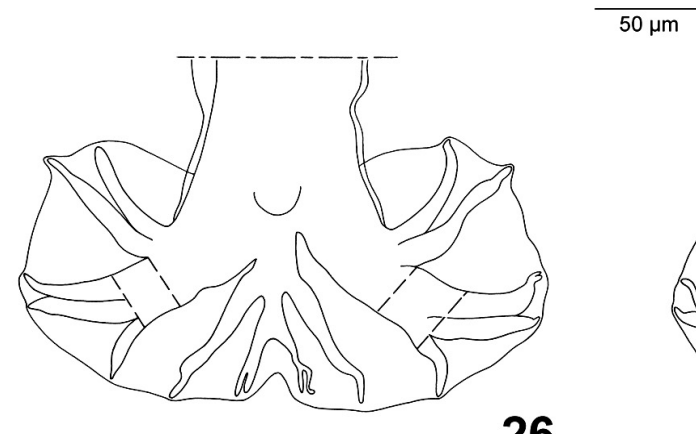

26

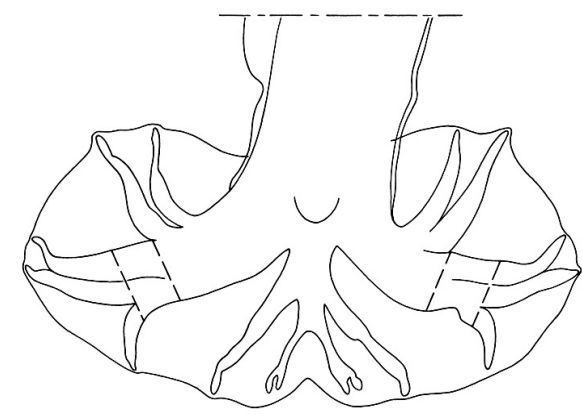

27
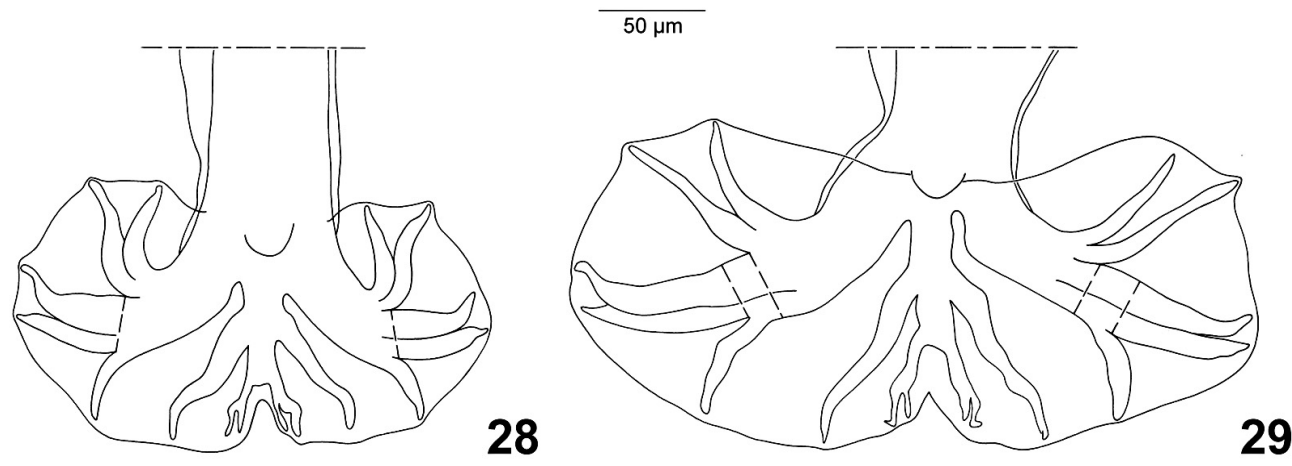

Figs 24-29. - Neoheligmonella granjoni $\mathrm{n}$. sp. Caudal bursa patterns of the latero ventral lobes in ventral view. 24-25 - from Mastomys natalensis. 26-28 - from M. erythroleucus. 29 - from $M$. buberti. In the three hosts the pattern is of type 2-3 with a tendency to type 2-21 i.e rays 2 and 3 are apposed and rays 4 to 6 have a common trunk (type 2-3) with a pattern tending towards type 2-2-1 since rays 6 separate first from this common trunk and rays 4 and 5 diverge distally at their extremity. The observed variations concern only the length of the common trunk of rays 4 to 6 . This length varies according to the lobe and /or the specimen. In Fig. 25, the common trunk is of equivalent size in both lobes, in Fig. 24, it is slightly longer in the right lobe, in Fig. 26, in the left lobe. In the right lobes of Figs 25 and 29 , it is reduced to the length of the base of ray 6 . In Fig. 28, the common trunk disappears since rays 6 diverge from common trunk of rays 2 to 6 at the same level as rays 3. In this case, the pattern of type 22-1 is observed.

Dotted lines indicate the length of the common trunk. Abbreviations: 2: ray $2 ; 3$ : ray $3 ; 4$ : ray $4 ; 5$ : ray $5 ; 6$ : ray 6 . dae, Nippostrongylinae). The genus is mainly characterised by the caudal bursa of type 2-3 tending towards type 2-2-1 or type 2-2-1 and by the synlophe with cuticular ridges of the left ventral quadrant being more developed than those of the right ventral quadrant. All the species are parasites of murine rodents, one from the Philippines and 20 from Africa, except for one species found in an arvicoline rodent from Thailand. Within this genus, the pattern of the caudal bursa is relatively homogeneous and the differentiation of the species is mainly supported by the features of the synlophe. The specimens described above belong to a group of species possessing the following features: large carene, ridge 6' (opposite the right lateral field) more developed than other right ridges; gradient of size decreasing from right to left on dorsal side; left ridges more developed than right ones on ventral side. They concern N. bai Diouf \& Durette-Desset, 2002, N. diel- mensis Diouf et al., 1998, both from Senegal and N. houini (Durette-Desset, 1970), from Ethiopia, all three species being parasites of Arvicanthis niloticus Geoffroy, 1903, N. capensis (Ortlepp, 1939) a parasite of Rhabdomys pumilio Sparrman, 1784 from South Africa, N. heimi (Desset, 1964) a parasite of Praomys jacksoni (de Winton, 1897) from the Central African Republic, N. mastomysi Diouf et al., 1998 a parasite of Mastomys erythroleucus from Senegal and N. schauenbergi Vaucher and Durette-Desset, 1984, a parasite of Phleomys cumingi Waterhouse, 1839 from the Philippines. The specimens described above are differentiated from all these species by 15 cuticular ridges at mid-body versus 13.

In $N$. bai, $N$. dielmensis and $N$. mastomysi the caudal bursal pattern is of type 2-3 with a tendency to type 2-2-1 as in our specimens. The three species mentioned above differ by a small carene and an inferior ratio spi- 
cules length/body length $(5.9 \%, 7.1 \%, 5.3 \%$, respectively versus 10 to $15 \%$ ).

Four of the five species whose synlophe is poorly described or unknown are differentiated from the Senegalese specimens by the ratio spicules length/body length. In $N$. kenyae (Yeh, 1958), a parasite of Rattus spp. from Kenya, this ratio is $7.5 \%$. In three species described by Baylis (1928) from Nigeria the ratio is $7.1 \%$ in N. impudica (Baylis, 1928), a parasite of Gerbilliscus kempi (Wroughton, 1906) (= Taterona kempi) and other Murinae, $8.5 \%$ in N. gracilis (Baylis, 1928), a parasite of Mus musculoides Temminck, 1853 (= Mus (Leggada) musculoides) and about $30 \%$ in N. moennigi (Baylis, 1928), a parasite of Praomys tullbergi (Thomas, 1894). The fifth species, N. affinis (Baylis, 1928), a parasite of Mastomys erythroleucus from Nigeria is closely related to the studied specimens not only by the ratio spicule length/body length (13.3\%) but also by the main measurements. Unfortunately there are no illustrations nor a description of the synlophe and it is not possible to compare the two species accurately and consequently to identify the Senegalese specimens with N. affinis.

We consider the specimens of Mastomys natalensis as belonging to a new species that we have named NeOheligmonella granjoni $\mathrm{n}$. sp.

\section{COMments}

The majority of the morphological variation observed in the three host species is considered as infra-specific since these variations are present within the specimens of the type material (Figs 18-23 for the synlophe, 2429 for the caudal bursa, Tables I-II-III). The specimen parasites of $M$. erythroleucus are the smallest. A possible explanation is that the infestation of M. erythroleucus is more recent since the worms continue to grow through out the whole of their life. The position of the excretory pore varies within each host but relative position in respect of the oesophagus length, overlaps in the three host species (Table III). The position of the deirids in respect to the head is very posterior in the specimens of $M$. natalensis but there is a great variability concerning the relative position of the position of the deirids with respect to the oesophagus length between the males and the females in each host. Moreover, preliminary molecular sequencing [12S: 508 base pairs (bp): $-28 S: 567+611+633$ bp, ITS2: $140+$ 220 bp]; of two Neoheligmonella individuals per Mastomys species showed very weak levels of molecular divergence between the specimens ( 0 to $0.3 \%$ of genetic distance).

To date, four species of Neoheligmonella have been described from the genus Mastomys with three species in M. erythroleucus: $N$. affinis, $N$. mastomysi, $N$. skirring $i$ Diouf et al., 1998 and one in M. natalensis: N. lamaensis Diouf et al., 2005. All these species come from Wes- tern Africa (Nigeria, Senegal, Benin) and share the same pattern of caudal bursa (that of $N$. affinis is not described): sub-symmetrical caudal bursa of type 2-3 with a tendency to type 2-2-1 for each lobe, rays 8 arising at the base of dorsal ray. Concerning the synlophe (except that of $N$. affinis, not described), all these species have a carene but the right ridge is well developed in $N$. mastomysi and $N$. granjoni, poorly developed in $N$. lamaensis and N. skirringi. The previous characters are shared with other Neoheligmonella which are not parasites of Mastomys spp. On the other hand, the same species $N$. granjoni parasitizes three different sympatric species of Mastomys. It appears that in the speciation of Neobeligmonella spp. parasitic in Mastomys spp. like in the genus Heligmonina, the geographical area may be of greater significance than the host species (Durette-Desset et al., 2007).

\section{HELIGMONINA KANEI N. SP. (Figs 30-38)}

Type and studied material: holotype male, allotype female, MNHN $669 \mathrm{KQb}$; four male, one female paratypes ZIT/IFAN 010 I, coparasites of Neoheligmonella granjoni $\mathrm{n}$. sp.

Type-host: Mastomys natalensis (Smith, 1834) (Muridae, Murinae) IRD $n^{\circ}$ CB 108.

Site: small intestine (SI 1-SI 2).

Type locality: Ndebou (12 31'05” N, $\left.12^{\circ} 26^{\prime} 01^{\prime \prime} \mathrm{W}\right)$, Kedougou, Republic of Senegal.

Etymology: in honour of Mamadou Kane, who helped with the recovery of the nematodes.

Voucher material: nine males, eight females in four M. natalensis, 11 males and 21 female in two M. buberti from the same region.

Prevalence and intensity of infection: in $M$. natalensis, five out of $220(2.3 \%)$ were infected with one to 17 worms (mean = 6); in M. erythroleucus, one of 263 $(0.4 \%)$ infected with one worm; in $M$. buberti two of $18(11.1 \%)$ infected with five to 127 worms $($ mean = 66).

\section{DESCRIPTION}

Small nematodes with body sinistrally coiled along ventral side. Excretory pore situated within median third of oesophagus length, deirids more distally within posterior quarter (Fig. 30). Oesophagus $11 \%$ on average in male and $8.5 \%$ in female. Short uterus taking up 15 to $17 \%$ of body length.

Head: cephalic vesicle present. In apical view, triangular oral opening surrounded by two amphids, four median external labial papillae and four median cephalic papillae (Fig. 31).

Synlophe (studied in two males and one female paratype): in both sexes, body bearing uninterrupted cuticular ridges except on right ventral side free of ridges. In both sexes, all ridges arising posterior to cephalic 
vesicle. In male ridge 6' disappearing anterior to midbody, other ridges at 70 anterior to caudal bursa. In female, ventral ridges disappearing anterior to vulvar opening, dorsal ridges posterior to it.

Presence of left hypertrophied ridge (left ala) curved towards ventral side in male, straight in female. In male, size of ala increasing progressively from cephalic vesicle to mid-body reaching 105 at this level (Fig. 33) then decreasing down abruptly to 50 (Fig. 38) before disappearing about 75 anterior to caudal bursa (Fig. 38). In female, size of left ala reaching 55 at mid-body (Fig. 35) and decreasing progressively down to 20 anterior to vulva.

Number of ridges: in both sexes 12 (ala, six dorsal, five ventral) in anterior part of body (Fig. 32) 11 (left ridge, six dorsal, four ventral) at mid-body (Figs 33, 35) and 10 (left ridge, five dorsal, four ventral) within posterior third of body (Fig. 34).

At mid-body, double gradient of size directed from left to right on ventral side and from right to left on dorsal side, with exception of ridge $n^{\circ} 1$ thin and longer than ridge $\mathrm{n}^{\circ} 2$ (Figs 33, 35).

Single axis of orientation directed from right ventral quadrant to left dorsal quadrant and inclined at $60^{\circ}$ to sagittal axis in male and $72^{\circ}$ in female.

- Holotype male: $2.65 \mathrm{~mm}$ long and 160 wide at midbody, left ala 65 included. Cephalic vesicle 60 long and

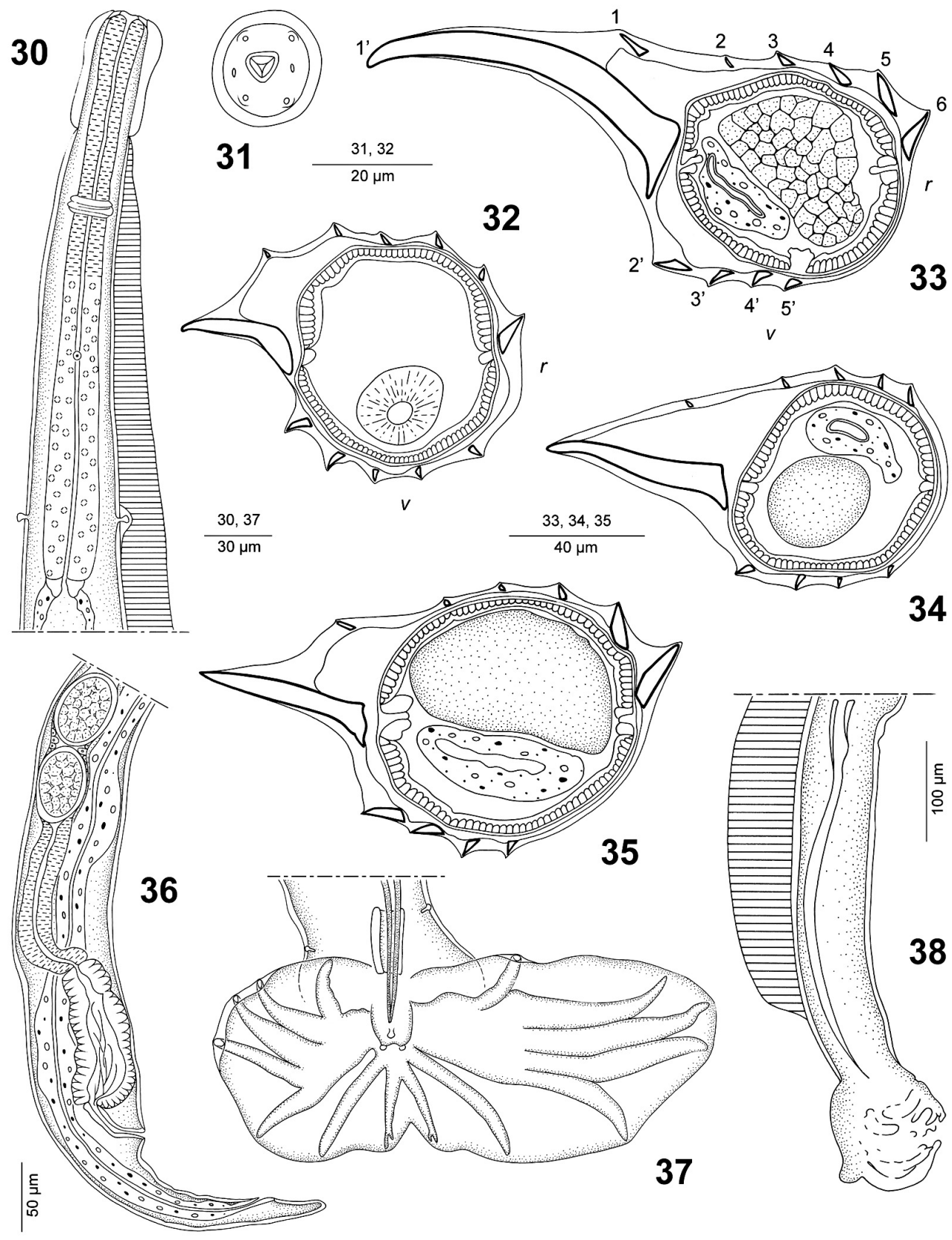

Figs 30-38. - Heligmonina kanei n. sp. from Mastomys natalensis (type host). 30-31 - female, 30 - anterior extremity, ventral view, 31 - head, apical view. 32-35 - transverse section at mid-body. 32-34 male, 32 - anterior to nerve ring, 33 - at mid-body, 34 $100 \mu \mathrm{m}$ anterior to caudal bursa. 35 - female, at midbody. 36 - female, posterior extremity, right lateral view. 37-38 - male, 37 - caudal bursa, ventral view, 38 - posterior extremity, disappearing of left ala, ventral view. Abbreviations: v: ventral side ; r: right side. All sections are orientated as 33 . 
30 wide. Nerve-ring, excretory pore and deirids situated at 100, 160 and 260 from apex, respectively. Oesophagus 310 long with muscular part 150 and glandular part 160.

Caudal bursa strongly asymmetrical with left lateral lobe most developed (Fig. 37). Pattern of caudal bursa of type 1-3-1 for right lobe and 1-4 for left lobe. Very small prebursal papillae not observed in all paratypes. Small rays 6. Rays 8 well developed slightly longer than dorsal ray arising symmetrically at its base. Dorsal ray deeply divided into two branches within its anterior third. Each branch divided into two small twigs, rays 9 (external branches) slightly longer than rays 10 (internal branches). Filiform spicules 350 long, with sharp tips. Spicules length/body length: 13,2\%. Rectangular gubernaculum 28 long and 17 wide at base. Genital cone 20 long and 23 at base with small elongated papilla 0 on ventral lip and two round papillae 7 on dorsal lip (Fig. 37).

Measurements (range and average) of four paratypes: 3.5 (2.65-3.55) $\mathrm{mm}$ long and 140 (130-145) wide, left ala 67, 5 (60-75) included. Cephalic vesicle, 59 (50-70) long and 29 (20-35) wide. Nerve ring, excretory pore and deirids situated at 100 (80-120), 182 (160-210) and 290 (260-320) from apex, respectively. Oesophagus 323 (265360) long. Spicules 355 (330-400) long, spicules length/ body length $11.6 \%$ (10.7-15.1). Gubernaculum 29 (2535) long and 14 (10-17) at base. Genital cone 18 (1520) long and 15 (10-20) wide at base.

- Allotype and paratype female: 4.2 (3.9) $\mathrm{mm}$ long and 150 (140) wide at mid-body, left ala 50 included. Cephalic vesicle 60 (60) long and 35 (30) wide. Nerve-ring, excretory pore and deirids situated at 85 (100) 140 (170) and 285 (300) from apex, respectively. Oesophagus 360 (340) long with muscular part 140 (150) and glandular part 240 (190) (Fig. 30). Monodelphic (Fig. 36): vulva situated at 180 (180) from caudal extremity, vagina vera 50 (40) long. Ovejector 225 (205) long with vestibule 80 (70) long, sphincter 25 (35) long and infundibulum 120 (100) long. Uterus 660 (650) long with seven (16) eggs at morula stage, 50 (70) long and 40 (40) wide. Uterus length/body length 15 (16.6) \%. Conical tail: 45 (50) long (Fig. 36).

\section{Diagnosis}

The specimens described above possess the same main features as the genus Heligmonina (Baylis 1928) (Heligmonellidae-Nippostrongylinae) redefined by DuretteDesset (1971). This genus is mainly characterised by the pattern of the synlophe with a hypertrophied left ala and a right ventral quadrant of the body lacking ridges totally or in parte. To date, 24 species have been described in this genus, all parasites of Muridae, 19 in Africa and five in Madagascar.

Three species, closely related to the material described above, both by the features of the synlophe and those of the caudal bursa pattern are all parasites of Mastomys spp. They concern H. bignonensis Diouf et al., 1997, a parasite of Mastomys erythroleucus from Senegal, H. chabaudi (Desset, 1964), a parasite of M. natalensis from the Congo and the Central African Republic and of Lemniscomys striatus (L., 1758) from the Congo, H. kotoensis Diouf et al., 2005, a parasite of Mastomys natalensis from Benin. As for the synlophe, the number of cuticular ridges is 11 with six dorsal and four ventral ridges at mid-body in both sexes and a double decreasing gradient of size from left to right for the ventral side and right to left for the dorsal side. For the right lobe, the pattern of the caudal bursa is of type 1-3-1 in all species. For the left lobe, the pattern is of type 1-3-1 with a tendency to type 1-4 (H. chabaudi) or else of type 1-4 (other species). H. chabaudi is also distinguished by the inclination of the axis of orientation to the sagittal axis $\left(45^{\circ}\right.$ versus $\left.70^{\circ}\right)$ as is the case of $H$. bignonensis. H. kotoensis is the most closely related species with a marked lengthening of the left lobe (about twice as long as the right lobe) and the same inclination of the axis of orientation.

The two species are differentiated by the width of the left ala which is smaller than the diameter of the body in H. kotoensis and greater in the specimens described above. In addition, in $H$. kotoensis the ratio of the spicule length on the body length is $16.8 \%$ on average and the distance anus-vulva is similar to that of the length of the tail. In the Senegalese specimens this ratio is $11.6 \%$ on average and the distance anus-vulva is about three times longer than that of the length of the tail. We consider the specimens parasitic in Mastomys natalensis as belonging to a new species that we have named Heligmonina kanei $\mathrm{n}$ sp.

\section{COMMENTS}

To date, a fourth species of Heligmonina has been described in the genus Mastomys. It concerns H. wakelini Durette-Desset et al., 2007, a parasite of M. natalensis from Swaziland which is morphologically more closely related to the Heligmonina spp. parasites of other Muridae from South Africa than the Heligmonina spp. parasites of Mastomys spp. from Western Africa. The presence of a new species of Heligmonina which is closely related to the Heligmonina spp. from Western Africa and not from other countries confirms the hypothesis of Durette-Desset et al. (2007) that in the speciation within this genus, the geographical location of the parasite may be of greater significance than the host spectrum. However, it is interesting to note that in the same geographical region (Western Africa) the species parasitic in Mastomys spp. are more closely related to each other than the species parasitic in other Muridae. The species of the genus have evolved with an increasingly asymmetry of the left lobe of the caudal bursa and an increasingly more pronounced 
inclination of the axis of orientation to the sagittal axis. In $H$. chabaudi, the common trunk of left rays $2-6$ is short and the caudal bursa is of type 1-3-1 with a tendency to type 1-4. Then, a progressive lengthening of the left common trunk produces the type 1-4 (a derived character state) in H. bignonensis, H. kotensis and lastly $H$. kanei. The axis of orientation is inclined at $45^{\circ}$ to the sagittal axis in H. bignonensis and $45-48^{\circ}$ in $\mathrm{H}$. chabaudi. The inclination is more pronounced in $H$. kotoensis $\left(70^{\circ}\right)$ and $H$. kanei. $\left(60^{\circ}\right.$ to $\left.72^{\circ}\right)$ which is considered a derived state character according to the patterns of the evolution of the synlophe proposed by DuretteDesset (1985), Durette-Desset \& Digiani, (2005).

\section{ACKNOWLEDGEMENTS}

W e wish to thank M. Samba Baidy Ndiaye, Dr Abdoul Aziz Niang and all the members of rodent team for their technical help, Khalilou Bâ, Anne Loiseau, Mamadou Kane and Coni Bâ for their help during field sampling. We also thank Caroline Tatard for her work in molecular sequencing.

\section{REFERENCES}

BAYLIS H.A. On a collection of Nematodes from Nigerian mammals (chiefly rodents). Parasitology, 1928, 20, 287-295.

Brouat C., Kane M., Diouf M., Bâ K., Sall-Dramé R. \& Duplantier J.M. Host ecology and variation in helminth community structure in Mastomys rodents from Senegal. Parasitology, 2007, 134, 437-450.

Brouat C \& Duplantier J.M. Host habitat patchiness and the distance decay of similarity among gastro-intestinal nematode communities in two species of Mastomys (South-eastern Senegal). Oecologia, 2007, 152, 715-720.

Desset M.C. Les systèmes d'arêtes cuticulaires chez les Nématodes Héligmosomes. Étude de cinq espèces parasites de Rongeurs de la Maboké. Cabiers de la Maboké, 1964, 2, 40-78.

Diouf M. \& Durette-Desset M.C. Two new species of Nippostrongylinae (Nematoda: Trichostrongylina) parasites of Cricetomys gambianus and Arvicanthis niloticus (Muridae) from Senegal. Parassitologia, 2002, 44, 97-101.

Diouf M., BÂ C.T. \& DuretTe-Desset M.C. Deux nouveaux Nippostrongylinae (Nematoda: Trichostrongylina) parasites de Muridae du Senegal. Zoosystema, 1997, 19, 223231.

Diouf M., BÂ C.T \& Durette-Desset M.C. Deux nouveaux Neoheligmonella (Nematoda: Trichostrongylina) parasites de Mastomys erythroleucus (Muridae) au Senegal. Zoosystema, 1998, 20, 23-30.

Diouf M., Daouda I. \& Durette-Desset M.C. - Two new Nippostrongylinae (Nematoda, Trichostrongylina) coparasites of Mastomys natalensis (Rodentia, Muridae) from Benin. Zoosystema, 2005, 27, 27-35.
Duplantier J.M., Granjon L. \& Bouganaly H. Reproductive characteristics of three sympatric species of Mastomys in Senegal, as observed in the field and in captivity. Mammalia, 1996, 60, 629-638.

Duplantier J.M., Granjon L. \& BÂ K. Répartition biogéographique des petits rongeurs au Sénégal. Journal of African Zoology, 1997, 111, 17-26.

DuretTE-Desset M.C. Les systèmes d'arêtes cuticulaires chez les Nématodes Héligmosomes. IV - Cinq nouvelles espèces parasites de Rongeurs africains. Cahiers de La Maboké, 1970, 8, 125-137.

DuretTe-Desset M.C. Essai de classification des Nématodes Héligmosomes. Corrélations avec la paléobiogéographie des hôtes. Mémoires du muséum National d'Histoire naturelle, nouvelle série, série A, Zoologie, 1971, 49, 1-126.

Durette-Desset M.C. Trichostrongyloid nematodes and their vertebrate host: reconstruction of the phylogeny of a parasitic group. Advances in Parasitology, 1985, 24, 239-306.

Durette-Desset M.C. \& Chabaud A.G. Nouvel essai de classification des Nématodes Trichostrongyloidea. Annales de Parasitologie Humaine et Comparée, 1981 56, 297-312.

DuretTe-Desset M.C. \& Chabaud A.G. Nomenclature des Strongylida au-dessus du groupe famille. Annales de Parasitologie Humaine et Comparée, 1993, 68, 111-112.

Durette-Desset M.C. \& Digiani M.C. The axis of orientation of the synlophe in the Heligmosomoidea (Nematoda: Trichostrongylina). New approach. Parasite, 2005, 12, 195202.

Durette-Desset M.C., Digiani M.C., Mahlaba T. \& Behnke J.M. Description of a new species of Heligmonina Baylis, 1928 (Nematoda: Trichostrongylina) a parasite of Mastomys natalensis (Muridae) from Swaziland and new data on the synlophe of Heligmonina chabaudi Desset, 1966. Parasite, 2007, 14, 271-280.

Granjon L. \& Duplantier J.M. Biogéographie insulaire et contraintes écologiques : le cas des rongeurs des îles du Saloum (Sénégal). Acta Oecologica, 1989, 10, 135-147.

Granjon L., Duplantier J.M., Catalan J. \& Britton-Davidian J. Systematics of the genus Mastomys (Thomas, 1915) (Rodentia: Muridae). Belgian Journal of Zoology, 1997, 127, S7S18.

GRATZ N. The burden of rodent-borne diseases in Africa South of the Sahara. Belgian Journal of Zoology, 1997, 127, 7184.

Hubert H. Dynamique des populations de deux espèces de rongeurs du Sénégal Mastomys erythroleucus et Taterillus gracilis (Rodentia, Muridae et Gerbillidae): I - Étude démographique. Mammalia, 1982, 46, 1-20.

Lecompte E., Granjon L., Kerbis Peterhans J. \& Denys C. Cytochrome b based phylogeny of the Praomys group 5 (Rodentia: Murinae): a new African radiation. Comptes Rendus de l'Académie des Sciences, Paris, série III, Sciences de la Vie, 2002, 325, 1-14.

LEIRS H. Population ecology of Mastomys natalensis (Smith, 1834). Implications for rodent control in Africa. Agricultural edition-Nr 35. A report from the Tanzania-Belgium Joint Research Project (1986-1989). Belgium Administration for Development Cooperation, Brussels, 1994. 
Musser G.G. \& Carleton M.D. Superfamily Muridoidea, in: Mammal species of the World, Wilson D.E. \& Reeder D.M. (Eds). The John Hopkins University Press, Baltimorre, $2^{\text {nd }}$ vol., 2005, 894-1531.

OrTLEPP R.J. South African helminths, Part VI. Some helminths, chiefly from rodents. Onderstepoort Journal of Veterinary Research, 1939, 12, 75-101.

VAucher C. \& DuRETTE-DesseT M.C. Neoheligmonella schauenbergi n. sp. (Nematoda : Trichostrongyloidea) parasite du Rat de Cuming Phloeomys cumingi Waterhouse. Revue Suisse de Zoologie, 1984, 90, 935-938.

YeH. On a new bursate nematode, Longistriata kenyae sp. nov. from the house rat, Rattus rattus kijabius in Kenya and the erection of a new genus Longistrioides. Journal of Helminthology, 1958, 32, 89-92.

Reçu le 12 décembre 2007 Accepté le 2 avril 2008 